\title{
Study Effect of Twist Multipliers on Loop Length, Loop Shape, and Tightness Factors of Single Jersey and $1 \times 1$ Rib Knitted Fabrics
}

\author{
Dereje Berihun Sitotaw and Kathirrvelu Subban Subramanian \\ Ethiopian Institute of Textile and Fashion Technology, Bahir Dar University, Bahir Dar, Ethiopia \\ Correspondence should be addressed to Dereje Berihun Sitotaw; dere96@yahoo.com
}

Received 20 June 2016; Accepted 14 August 2016

Academic Editor: Ricardo Molina

Copyright (c) 2016 D. B. Sitotaw and K. S. Subramanian. This is an open access article distributed under the Creative Commons Attribution License, which permits unrestricted use, distribution, and reproduction in any medium, provided the original work is properly cited.

\begin{abstract}
The study focuses on effect of twist multiplier on single jersey and $1 \times 1$ rib knitted fabrics loop length, loop shape, and tightness factors properties. For the study $100 \%$ cotton fiber which is processed into $40 \mathrm{Ne}$ (English count) carded ring spun yarn is used. Three twist levels of 900 turns $/ \mathrm{m}, 1050$ turns $/ \mathrm{m}$, and 1200 turns $/ \mathrm{m}$ with respective twist multipliers of 3.6, 4.2, and 4.8 are used. The single jersey produced from the three twist multipliers is named as $\mathrm{Sj} 1$ which is produced from 3.6, $\mathrm{Sj} 2$ from 4.2, and $\mathrm{Sj} 3$ from 4.8 . Similarly, $1 \times 1$ rib is denoted as R1 which is produced from 3.6, R2 from 4.2, and R3 from 4.8. The test was performed as per ASTM D1776-Practice for Conditioning Textiles for Testing. The tests done for ten specimens and the results showed that loop length, loop shape, and tightness factors properties of single jersey and $1 \times 1$ rib knitted fabrics are significantly influenced by twist multipliers variation.
\end{abstract}

\section{Introduction}

The dimensional properties of knitted fabrics are vital in apparel application of knitted fabrics. These properties are dependent on loop length to high extent. The dimensional properties include loop length, wales and courses per unit length, stitch density, loop shape factor, take-up rate, and fabric width.

Loop lengths combine in the form of course lengths and it is these that influence fabric dimensions and other properties, including weight. Variations in course length between one garment and another can produce size variations, whilst course length variations within structures (particularly when using continuous filament yarns) can produce horizontal bareness and adversely affect the appearance of the fabric $[1,2]$.

Weft knitted structures, especially those used for hosiery, knitwear, and underwear, have unique properties of formfitting and elastic recovery based on the ability of knitted loops to change shape when subjected to tension. Unfortunately, dimensional changes can also occur during production, or washing and wearing, as problems of shrinkage and size variation can cause customer dissatisfaction and increased production costs [1].

The single jersey knitted fabric properties especially the dimensional and physical characteristics are mainly influenced by the constituent fibers, yarn properties, knitting machine variables, processing, and finishing treatments. Abdel Megeid et al. [3] and Munden [4] have extensively investigated the dimensional properties of wool and cotton knitted fabrics and predicted that the length of the yarn in the knitted loop plays a major role in determining the dimensions of knitted fabrics.

Yarn properties such as linear densities of yarns play a vital role in the dimension of weft knitted fabrics as they control the level of shrinkage in the yarn. Using coarser yarns will result in tighter knitted fabrics. This in turn influences the fabric loop length and loop shape factor properties. Loop length and tightness factors together with twist multipliers have an effect on air permeability property of single jersey and $1 \times 1$ rib knitted fabrics. 
But researchers do not show the effect of twist multiplier on knitted fabrics dimensional properties such as on loop length, loop shape factor, and tightness factor. This paper mainly focuses on the analysis of twist multipliers effect on single jersey and $1 \times 1$ rib knitted fabrics dimensional properties.

\section{Methodology}

2.1. Methods. This research is designed to study the effect of yarn twist on the loop length, loop shape, and tightness factors properties of single jersey and $1 \times 1$ rib knitted fabrics by collecting different data and samples. Cotton is the dominant fiber for circular knitting machines in Ethiopia and its properties such as staple length, short fiber index, nep, trash \%, and origin are identified for this study. The yarn process parameters, excluding yarn twist, are controlled, with constant value. The fabric properties which are planned to be studied in this paper are produced from variety of yarn twist with the same material, machine setting, and process parameters. The methods for this work are clearly listed below.

(i) Produce yarn with different twist level and keep other yarn process parameters constant.

(ii) Study yarn properties by carrying out proper testing.

(iii) Produce knitted fabrics from the three different twist levels of yarn.

(iv) Study the fabric loop length, loop shape, and tightness factor properties by carrying out proper testing.

(v) Analyze the results obtained from testing using Microsoft Office excel and one way ANOVA from SPSS.

The data related to this research work is collected from MAA garment and textile factory and EiTEX laboratory (both are found in Ethiopia). Relevant data related to the effect of yarn twist on knitted fabric properties include fiber properties, spinning machine parameters, yarn property, knitting machine parameters, knitted fabric types, and test results are collected.

2.2. Materials and Equipment. The materials and equipment listed in Table 1 are used to measure the yarn and fabric properties for this research work.

2.2.1. Fiber Properties. Fiber properties mentioned were considered to produce the sample yarn and fabrics. These fiber properties were kept constant for the yarn production. Cotton fiber is used in this study for it is the dominant raw material in textile factories especially in Ethiopia. The test is done randomly by taking samples from five different bales and the average results are shown in Table 2 .

2.2.2. Spinning Machine Parameters. The spinning machine parameters included in this work are related to ring spinning machine. For this purpose ring spinning machine was used.
TABLE 1: Equipments and materials used.

\begin{tabular}{lccc}
\hline S/r number & $\begin{array}{c}\text { Name of } \\
\text { equipment }\end{array}$ & Tests & Located in \\
\hline 1 & $\begin{array}{c}\text { Atlas twist } \\
\text { tester } \\
\text { Atlas count } \\
\text { tester }\end{array}$ & $\begin{array}{c}\text { Twist } \\
\text { Linear density of } \\
\text { yarn } \\
\text { U\%, CVM, thin, } \\
\text { thick, Nep } \\
\text { GSM, abrasion, } \\
\text { Uster tester-5 }\end{array}$ & MAA \\
4 & MAA, EiTEX \\
5 & $\begin{array}{c}\text { Cutting dies } \\
\text { Crimp tester } \\
\text { Universal } \\
\text { tensile }\end{array}$ & $\begin{array}{c}\text { Loop length } \\
\text { Yarn tensile } \\
\text { strength and } \\
\text { tester for yarn }\end{array}$ & EiTEX \\
& elongation & EiTEX \\
\hline
\end{tabular}

In MAA garment and textile factory (Ethiopia) there are ten ring frame machines of which five are for combed yarn and five for carded yarn. The machines are from RIETER Switzerland with the model G33 ${ }^{+}$. The following lists of data are about ring spinning machine which are used to produce the yarns with it for the sample fabric production:

(i) Machine type: RIETER G33+

(ii) Material: carded, $100 \%$ cotton

(iii) Twist: 900, 1050 and 1200

(iv) Twist Factor: 3.6, 4.2 and 4.8

(v) RPM: 16000

(vi) Traveler: 25

(vii) Spacer: 3.0 (White)

(viii) Break Draft: 1.19 (69T)

2.2.3. Yarn Parameters. As the research was already done to study the effect of yarn twist on knitted fabric properties by testing the yarn and fabric sample using Zweigle Uster Tester standard and is used for analysis of the yarn properties related to twist effect. The yarn strength and elongation properties were measured by using Universal Strength Tester at $50 \mathrm{~cm}$ gauge length and $20 \mathrm{sec}$ time to break. The data collected from MAA during yarn production with different twist levels are indicated in Table 3.

2.2.4. Knitting Machine Parameters. The two fabrics are produced with the machine parameters as indicated in Table 4. The fabrics for this study are produced on circular knitting machine.

2.2.5. Produced Fabric Parameters. The fabrics produced to be studied in this research are single jersey and $1 \times 1 \mathrm{rib}$ knitted fabrics produced from three different twist multipliers. The sample fabrics are produced with one roll of fabrics from each twist multipliers and 3 meters of fabrics are taken from each type to be tested. The fabrics are produced with the machine parameter as shown in Table 4. 
TABLE 2: Fiber properties.

\begin{tabular}{llccccc}
\hline Type of fiber & Origin & Staple length & Short fiber index & Nep & Trash\% & Micronaire \\
\hline Cotton $(100 \%)$ & Indian & 30.6 & 10.4 & 207.4 & 3.58 & 3.78 \\
\hline
\end{tabular}

TABLE 3: Yarn properties.

\begin{tabular}{lcccccccccc}
\hline Machine type & $\begin{array}{c}\text { Machine } \\
\text { number }\end{array}$ & Twist (1/m) & Ne & U\% & CVM & $\begin{array}{c}\text { Thin } \\
-50 \%\end{array}$ & $\begin{array}{c}\text { Thick } \\
+50 \%\end{array}$ & $\begin{array}{c}\text { Neps } \\
+200 \%\end{array}$ & $\begin{array}{c}\text { Strength } \\
(\mathrm{cN} / \text { Tex })\end{array}$ & $\begin{array}{c}\text { Elongation } \\
(\%)\end{array}$ \\
\hline \multirow{2}{*}{ Ring frame } & & 900 & & 13.97 & 17.90 & 38.8 & 612.8 & 844 & 1.17 & 4.76 \\
& & 1050 & 40 & 13.88 & 17.83 & 31.6 & 646.8 & 827.8 & 1.68 & 4.33 \\
& 07 & 1200 & & 13.53 & 17.37 & 24.4 & 557.6 & 791.6 & 1.89 & 3.92 \\
\hline
\end{tabular}

\section{Experimental Study of Single Jersey and $1 \times 1$ Rib Knitted Fabrics Loop Length, Loop Shape, and Tightness Factor Properties}

The knitted fabric properties to be studied in this research work are the dimensional properties. The study was done in the following order: loop length, loop shape, and tightness factor properties. The test was done as per American Society Standard for Testing and Materials (ASTM). With this standard many of the tests are done for ten specimens at the standard atmospheric condition at $21 \pm 1^{\circ} \mathrm{C}$ and $65 \pm 2 \%$ at EiTEX laboratory (ASTM D1776-98).

3.1. Determination of Loop Length, Loop Shape, and Tightness Factor Properties. Effect of yarn twist on knitted fabric loop length, loop shape, and tightness factor properties is studied. The study was carried out on dry relaxed state of single jersey and $1 \times 1$ rib knitted fabrics.

3.1.1. Knitted Fabric Loop Length. Loop length is the fundamental unit of weft knitted structure [1]. Stitch/loop length is the fundamental unit which controls all the properties of weft knitted fabrics. Mainly stitch length and knit structure affect all the dimensional, comfort, handle, and other properties $[2,5,6]$. The loop length was calculated using the crimp tester and measuring the unraveled yarn for ten courses for each twist level. The equipment for this test including crimp tester, scissor, and pick glass is used. Loop length is found by dividing the stretched yarn length by the number of loops in one course and expressed as follows:

Loop length $(l)=$ uncrimped yarn length in one course/number of loops in one course $(n)$ [3].

The results of the test are shown in Table 5.

3.1.2. Loop Shape Factor. Loop shape determines the dimensions of the fabric, and this shape depends upon the yarn used and the treatment that the fabric has received [1, 7]. The loop shape factor of single jersey and $1 \times 1 \mathrm{rib}$ knitted fabrics is found from the mean results of wales and courses per unit length. It is determined by dividing the courses per centimeter by the wales per centimeter.
Loop shape factor $(R)=$ CPCM/WPCM, where CPCM is courses per centimeter and WPCM is wales per centimeter. So, $\mathrm{R}$ values are calculated from Tables 6 and 7 and the loop shape results are shown in Table 8 .

3.1.3. Tightness Factor. This property is required to measure the closeness and openness of knitted fabrics. In general it is a measure of level of fabric density $[4,8]$. It is represented by $K$ and expressed as follows:

$K=\sqrt{\text { tex }}$ loop length $(l)$, and Table 9 shows the results of tightness factor which is found from the average of loop length.

\section{Discussion}

The study focuses on yarn twist multiplier effect on single jersey and rib $1 \times 1$ knitted fabrics loop length, loop shape, and tightness factor properties. Based on these factors, the analysis was done related to the loop length, loop shape, and tightness factors. For the analysis, one way ANOVA in SPSS and Excel are used. And we formulated the hypothesis for this study since statistical data cannot substitute engineering/science. It was formulated that

(1) twist multipliers have an effect on knitted fabrics dimensional properties such as loop length, loop shape factor, and tightness factor because change in twist level brings change in yarn density, softness, smoothness, thickness, and evenness;

(2) the dimensional properties of the two fabrics will be affected by twist multiplier. Twist multiplier is inversely proportional to loop length and loop shape factor and directly proportional to the tightness factor of single jersey and $1 \times 1$ rib knitted fabrics dimensional properties.

4.1. Loop Length. As shown in Table 5 loops length decreased as the twist multiplier increased. The average loop length for single jersey fabrics is $3.648 \mathrm{~mm}$ at 900 turns $/ \mathrm{m}, 3.3$ at 1050 turns $/ \mathrm{m}$, and $3.034 \mathrm{~mm}$ at 1200 turns $/ \mathrm{m}$. And rib 1 $\times 1$ knitted fabrics have loop length 3.657 at 900 turns/m, $3.569 \mathrm{~mm}$ at 1050 turns/m, and $3.443 \mathrm{~mm}$ at 1200 turns $/ \mathrm{m}$. 


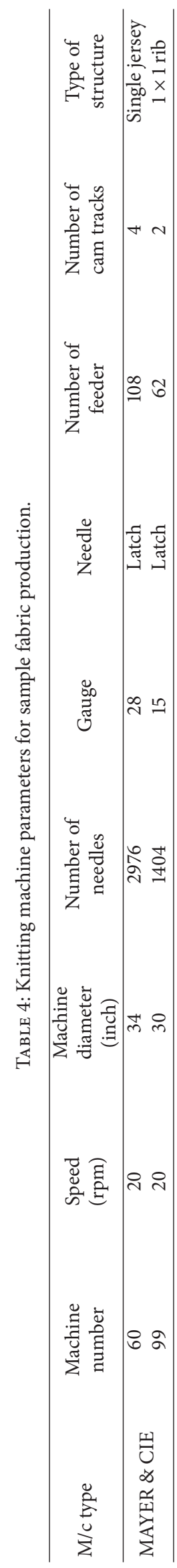


TABLE 5: Loop length.

\begin{tabular}{|c|c|c|c|c|c|c|c|c|c|c|c|c|}
\hline \multirow{2}{*}{ Fabric type } & \multirow{2}{*}{ Sample number } & \multicolumn{10}{|c|}{ Loop length $(\mathrm{mm})$} & \multirow{2}{*}{ Average } \\
\hline & & 1 & 2 & 3 & 4 & 5 & 6 & 7 & 8 & 9 & 10 & \\
\hline \multirow{3}{*}{ Single jersey } & Sj1 & 3.7 & 3.6 & 3.7 & 3.7 & 3.7 & 3.6 & 3.66 & 3.62 & 3.64 & 3.7 & 3.648 \\
\hline & $\mathrm{Sj} 2$ & 3.3 & 3.3 & 3.3 & 3.4 & 3.3 & 3.3 & 3.28 & 3.3 & 3.28 & 3.3 & 3.3 \\
\hline & $\mathrm{Sj} 3$ & 3 & 3.11 & 3 & 3.1 & 3 & 3 & 3.11 & 3.11 & 3 & 3 & 3.034 \\
\hline \multirow{3}{*}{ Rib $1 \times 1$} & $\mathrm{R} 1$ & 3.7 & 3.66 & 3.7 & 3.6 & 3.7 & 3.7 & 3.63 & 3.66 & 3.69 & 3.7 & 3.657 \\
\hline & $\mathrm{R} 2$ & 3.6 & 3.59 & 3.6 & 3.5 & 3.6 & 3.6 & 3.57 & 3.6 & 3.59 & 3.6 & 3.569 \\
\hline & R3 & 3.4 & 3.41 & 3.5 & 3.5 & 3.4 & 3.5 & 3.46 & 3.46 & 3.45 & 3.5 & 3.443 \\
\hline
\end{tabular}

TABLE 6: Wales per centimeter.

\begin{tabular}{|c|c|c|c|c|c|c|c|c|c|c|c|c|}
\hline \multirow{2}{*}{ Fabric type } & \multirow{2}{*}{ Sample number } & \multicolumn{10}{|c|}{ Wales per centimeter $\left(\mathrm{cm}^{-1}\right)$} & \multirow{2}{*}{ Average } \\
\hline & & 1 & 2 & 3 & 4 & 5 & 6 & 7 & 8 & 9 & 10 & \\
\hline \multirow{3}{*}{ Single jersey } & Sj1 & 12 & 12 & 12 & 11 & 11 & 12 & 11 & 11.5 & 12 & 11 & 11.45 \\
\hline & $\mathrm{Sj} 2$ & 16 & 13 & 15 & 14 & 15 & 15 & 14 & 15.5 & 13 & 15 & 14.5 \\
\hline & $\mathrm{Sj} 3$ & 16 & 16.5 & 17 & 17 & 16 & 18 & 16.5 & 18 & 16 & 16 & 16.7 \\
\hline \multirow{3}{*}{ Rib $1 \times 1$} & $\mathrm{R} 1$ & 17 & 17 & 17 & 17 & 17 & 17 & 17 & 17 & 17 & 17 & 17 \\
\hline & $\mathrm{R} 2$ & 17 & 21 & 19 & 19 & 18 & 20 & 19 & 21 & 20 & 18 & 19.2 \\
\hline & R3 & 23 & 22 & 22 & 23 & 24 & 23 & 23 & 24 & 23 & 24 & 23.1 \\
\hline
\end{tabular}

TABLE 7: Courses per centimeter.

\begin{tabular}{|c|c|c|c|c|c|c|c|c|c|c|c|c|}
\hline \multirow{2}{*}{ Fabric type } & \multirow{2}{*}{ Sample number } & \multicolumn{10}{|c|}{ Courses per centimeter $\left(\mathrm{cm}^{-1}\right)$} & \multirow{2}{*}{ Average } \\
\hline & & 1 & 2 & 3 & 4 & 5 & 6 & 7 & 8 & 9 & 10 & \\
\hline \multirow{3}{*}{ Single jersey } & Sj1 & 15 & 16 & 15 & 15 & 16 & 15 & 16 & 15 & 16 & 16 & 15.5 \\
\hline & $\mathrm{Sj} 2$ & 16 & 18 & 15 & 17 & 17 & 16 & 17 & 16 & 16 & 17 & 16.5 \\
\hline & $\mathrm{Sj} 3$ & 15 & 17 & 18 & 18 & 18 & 17 & 18 & 16 & 17 & 18 & 17.2 \\
\hline \multirow{3}{*}{ Rib $1 \times 1$} & $\mathrm{R} 1$ & 10 & 11 & 11 & 11 & 10 & 11 & 10 & 10 & 11 & 11 & 10.6 \\
\hline & $\mathrm{R} 2$ & 12 & 11 & 12 & 11 & 12 & 12 & 12 & 12 & 11 & 12 & 11.7 \\
\hline & R3 & 13 & 12 & 12 & 12 & 13 & 12 & 13 & 13 & 13 & 12 & 12.5 \\
\hline
\end{tabular}

TABLE 8: Loop shape factor for single jersey and rib $1 \times 1$.

\begin{tabular}{lcc}
\hline Fabric type & Sample number & $R$ \\
\hline \multirow{3}{*}{ Single jersey } & Sj1 & 1.35 \\
& Sj2 & 1.14 \\
& Sj3 & 1.03 \\
\hline \multirow{2}{*}{ Rib $1 \times 1$} & R1 & 0.62 \\
& R2 & 0.61 \\
& R3 & 0.54 \\
\hline
\end{tabular}

TABLE 9: Tightness factor.

\begin{tabular}{lcc}
\hline Fabric type & Sample number & $K($ tex $/ \mathrm{mm})$ \\
\hline \multirow{3}{*}{ Single jersey } & $\mathrm{Sj} 1$ & 1.7 \\
& $\mathrm{Sj} 2$ & 1.9 \\
& $\mathrm{Sj} 3$ & 2.1 \\
\hline \multirow{2}{*}{ Rib $1 \times 1$} & $\mathrm{R} 1$ & 1.7 \\
& $\mathrm{R} 2$ & 1.8 \\
& $\mathrm{R} 3$ & 2.01 \\
\hline
\end{tabular}

The fabrics are made from $40 \mathrm{Ne}$ yarn with different twist level and loop length was varied.

This is due to the unwinding tension becoming more and the needle is not able to bend the yarn easily to intermesh with high twist level as compared to low twist yarn. So the needle fails to receive sufficient yarn and robbing back will be more than receiving from the feeder. Due to this robbing back, the loop length reduced with high twist of yarn. This in turn affects wales per centimeter and courses per centimeter. The mean differences between loop lengths in the single jersey and rib knitted fabrics produced from the three twist multipliers are significantly different as shown in multiple comparisons Table 10 with different effect level on the two fabrics.

Figure 1 shows the effect of twist multiplier on loop length of the two fabrics and as observed from Table 11, loop lengths of the two fabrics brought from the three twist multipliers are greatly independent of each other and have significantly different effect on loop length of the single jersey $(F=$ 558.920, $P=0.000)$ and rib $1 \times 1(F=137.548, P=0.000)$ knitted fabrics. 
TABLE 10: Multiple comparisons of loop lengths of knitted fabrics produced from three twist multipliers.

\begin{tabular}{|c|c|c|c|c|c|}
\hline $\begin{array}{l}\text { Dependent } \\
\text { variable }\end{array}$ & $\begin{array}{l}\text { (I) Knitted fabrics } \\
\text { produced from } \\
\text { different twist level }\end{array}$ & $\begin{array}{l}(J) \text { Knitted fabrics } \\
\text { from the three } \\
\text { twist multipliers } \\
\text { twist level }\end{array}$ & $\begin{array}{l}\text { Mean difference } \\
\qquad(I-J)\end{array}$ & Std. error & Sig. \\
\hline \multirow{6}{*}{$\begin{array}{l}\text { Loop length of } \\
\text { single jersey (mm) }\end{array}$} & \multirow{2}{*}{900} & 1050 & $.34800^{*}$ & .01842 & .000 \\
\hline & & 1200 & $.61400^{*}$ & .01842 & .000 \\
\hline & \multirow{2}{*}{1050} & 900 & $-.34800^{*}$ & .01842 & .000 \\
\hline & & 1200 & $.26600^{*}$ & .01842 & .000 \\
\hline & \multirow{2}{*}{1200} & 900 & $-.61400^{*}$ & .01842 & .000 \\
\hline & & 1050 & $-.26600^{*}$ & .01842 & .000 \\
\hline \multirow{6}{*}{$\begin{array}{l}\text { loop length of rib } \\
(\mathrm{mm})\end{array}$} & \multirow{2}{*}{900} & 1050 & $.08800^{*}$ & .01297 & .000 \\
\hline & & 1200 & $.21400^{*}$ & .01297 & .000 \\
\hline & \multirow{2}{*}{1050} & 900 & $-.08800^{*}$ & .01297 & .000 \\
\hline & & 1200 & $.12600^{*}$ & .01297 & .000 \\
\hline & \multirow{2}{*}{1200} & 900 & $-.21400^{*}$ & .01297 & .000 \\
\hline & & 1050 & $-.12600^{*}$ & .01297 & .000 \\
\hline
\end{tabular}

* shows that the effect is significant and not by laboratory errors.

TABLE 11: Analysis of variance for loop lengths of single jersey and rib $1 \times 1$ knitted fabrics.

\begin{tabular}{|c|c|c|c|c|c|c|}
\hline & & Sum of squares & Df & Mean square & $F$ & Sig. \\
\hline \multirow{3}{*}{ loop length of single jersey $(\mathrm{mm})$} & Between groups & 1.896 & 2 & .948 & 558.920 & .000 \\
\hline & Within groups & .046 & 27 & .002 & & \\
\hline & Total & 1.942 & 29 & & & \\
\hline \multirow{3}{*}{ loop length of rib (mm) } & Between groups & .231 & 2 & .116 & 137.548 & .000 \\
\hline & Within groups & .023 & 27 & .001 & & \\
\hline & Total & .254 & 29 & & & \\
\hline
\end{tabular}

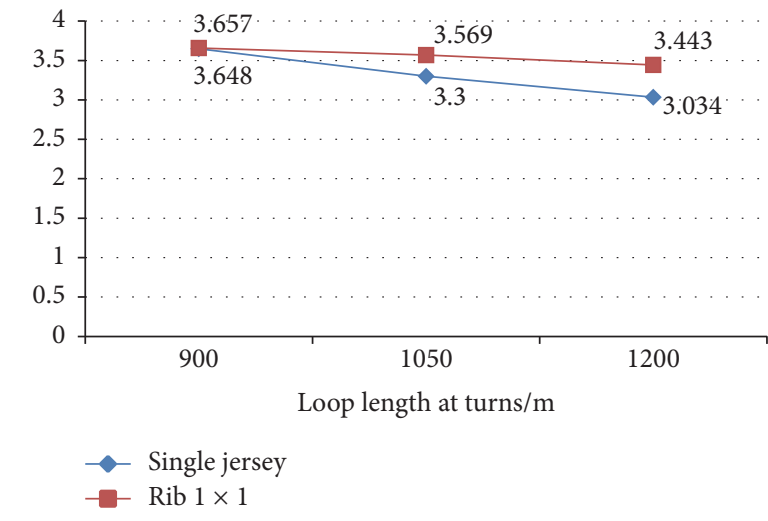

FIGURE 1: Loop length of single jersey and $1 \times 1$ rib knitted fabrics.

4.2. Loop Shape Factor. As shown in Table 8 and Figure 2, loop shape factor varies as the twist multiplier varies. The loop shape reduces as the twist multiplier increases. Twist multiplier increases mean that the loop shape will become unclear and it affects the loop shape factor which is controlled during relaxation. So, knitted fabrics loop shape will be better in any type of relaxation state with lower twist multiplier.

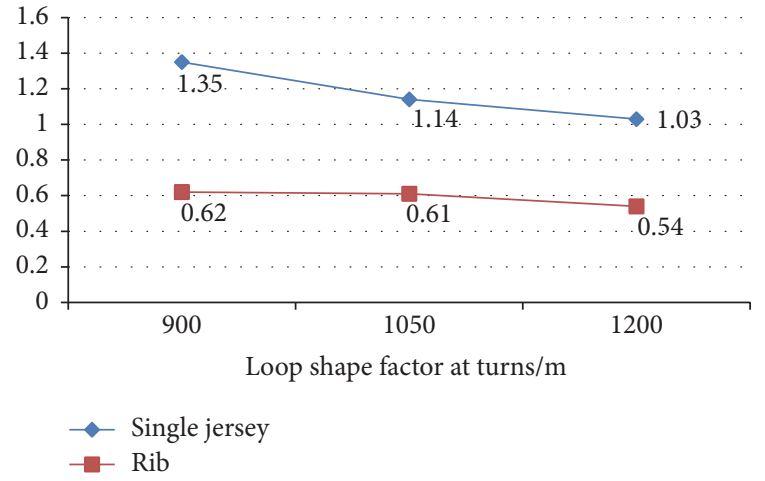

FIGURE 2: Loop shape factor single jersey and rib $1 \times 1$ at 900, 1050, and 1200 turns/m.

4.3. Fabric Tightness Factor. Tightness factor of knitted fabric was determined by calculation from yarn linear density and loop length. The yarn linear density is constant, that is, $40 \mathrm{Ne}$, but the loop length varies according to the level of TM which results in different tightness factor of knitted fabric. Tightness factor of single jerseys and $1 \times 1$ rib knitted fabrics attained different tightness between structures. 


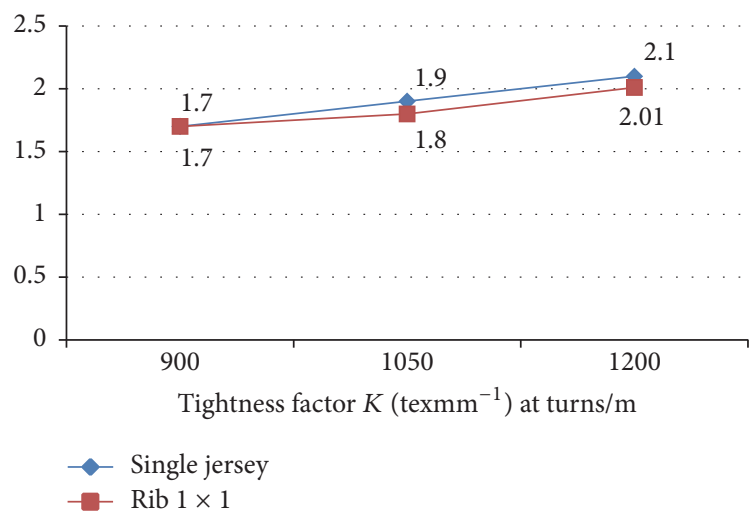

FIGURE 3: Effect of TM on tightness factor of knitted fabrics.

As shown in Table 9, single jersey produced from 900 turns/m (Sj1 TM = 3.6) has $1.73 \mathrm{tex} / \mathrm{mm}$, single jersey produced from 1050 turns/m $(\mathrm{Sj} 2 \mathrm{TM}=4.2)$ has $1.92 \mathrm{tex} / \mathrm{mm}$, and single jersey produced from 1200 turns $/ \mathrm{m}$ has $2.08 \mathrm{tex} / \mathrm{mm}$ tightness factor $(k)$.

Similarly $1 \times 1 \mathrm{rib}$ fabric produced from 900 turns $/ \mathrm{m}$ has $1.73 \mathrm{tex} / \mathrm{mm}$, that of $1 \times 1 \mathrm{rib}$ produced from 1050 has $1.77 \mathrm{tex} / \mathrm{mm}$, and rib $1 \times 1$ produced from 1200 turns $/ \mathrm{m}$ has $1.84 \mathrm{tex} / \mathrm{mm}$ tightness factor. All the data are found from $40 \mathrm{Ne}$ of yarn count and average loop length.

As shown in Figure 3 effect of twist multiplier is different on these two structures. Single jersey is affected greatly compared to rib. The difference between tightness factors of knitted fabrics produced from low twist level and high twist level is $0.35 \mathrm{tex} / \mathrm{mm}$ in single jersey and $0.11 \mathrm{tex} / \mathrm{mm}$ in $1 \times$ $1 \mathrm{rib}$. This shows that tightness factor is highly affected in single jersey compared to in rib by TM. Even though twist multiplier has influence on knitted fabrics the level of effect is different according to the type of structure and this because rib fabrics have balanced structure and loop length difference approaches one to the other. Single jersey knitted fabric was exposed greatly to robbing back of yarn.

\section{Conclusion}

Twist multipliers effects on loop length, loop shape, and tightness factors of single jersey and $1 \times 1$ rib knitted fabrics were studied in this paper and the effect is shown from the result and analysis in tables and figures. The study shows that the effect of twist multiplier on loop length, loop shape, and tightness factors properties of single jersey and $1 \times 1 \mathrm{rib}$ knitted fabrics is significant. The effect is seen on loop length where TM significantly influences the loop length of the two fabrics. This is because of the unwinding tension increases with an increase in TM, and the knitting needles fail to receive an optimum yarn length for the adjusted loop length before it reaches the needle running position (after loop length formation position or loop length pulling position). The other reason for loop length, tightness, and loop shape factors of the two fabrics' variation is the yarn elongation property. The yarn elongation property (Table 3 ) was reduced with an increase in twist multiplier. This elongation reduction in yarn results in loop length reduction of the two fabrics. This in turn influences the loop shape and tightness factors of the single jersey and $1 \times 1$ rib knitted fabrics.

The loop length of both single jersey and $1 \times 1 \mathrm{rib}$ knitted fabrics reduced with an increase in TM and the mean differences in loop lengths of the single jersey and rib 1 $\times 1$ knitted fabrics produced from the three different twist multipliers (TM) are significantly different.

The other two properties (loop shape and tightness factors) are also affected by twist multipliers for loop length is significantly influenced. Since the tightness factor property is inversely proportional to loop length, as twist multiplier increases the tightness factor increases. But loop shape factor reduces with an increase in twist multipliers due to high fabric shrinkage and the relaxation in dry state on high twist level is not effective.

This research work will help for knitted fabric manufacturers. If the knitting factory technologists are aware of effect of twist multipliers on knitted fabrics loop length, loop shape, and tightness factors, they can take measure for the appropriate material selection. Modeling of loop shape and tightness factors in relation to yarn twist multipliers and twist multiplier and relaxations effect on loop length, loop shape, and tightness factors are open for further research works.

\section{Competing Interests}

The authors declare that there is no conflict of interests regarding the publication of this paper.

\section{References}

[1] D. J. Spencer, Knitting Technology, A Comprehensive Handbook and Practical Guide, Woodhead Publishing; Technomic Publishing, 3rd edition, 2001.

[2] S. C. Anand, K. S. M. Brown, L. G. Higgins, D. A. Holmes, M. E. Hall, and D. Conrad, "Effect of laundering on the dimensional stability and distortion of knitted fabrics," Autex Research Journal, vol. 2, no. 2, pp. 85-100, 2002.

[3] Z. M. Abdel Megeid, M. Al-Bakry, and M. Ezzat, "The influence of stitch length of weft knitted fabrics on the sewability," Journal of American Science, vol. 7, no. 8, pp. 610-617, 2011.

[4] D. L. Munden, "The geometry and dimensional properties of plain knit fabrics," Journal of the Textile Institute Transactions, vol. 50, no. 7, pp. 448-471, 1959.

[5] E. H. Nizam and A. Hossain, "The relationship between stitch length and fabric diameter (open width) of single jersey, $1 \times 1$ Rib and $1 \times 1$ interlock," International Journal of Engineering Research \& Technology, vol. 4, no. 4, 2015.

[6] N. Gokarneshan, S. R. Viswanath, V. B. Nagarajan, and J. Veeraprabhakar, "Dimensional characteristics of cotton and viscose weft knits," International Journal of Innovative Research and Review, vol. 3, no. 3, pp. 84-103, 2015.

[7] P. J. Doyle, "Fundamental aspects of the design of knitted fabrics," Journal of the Textile Institute, vol. 44, pp. 561-573, 1953.

[8] C. N. Herath, B. C. Kang, and H.-Y. Jeon, "Dimensional stability of cotton-spandex interlock structures under relaxation," Fibers and Polymers, vol. 8, no. 1, pp. 105-110, 2007. 

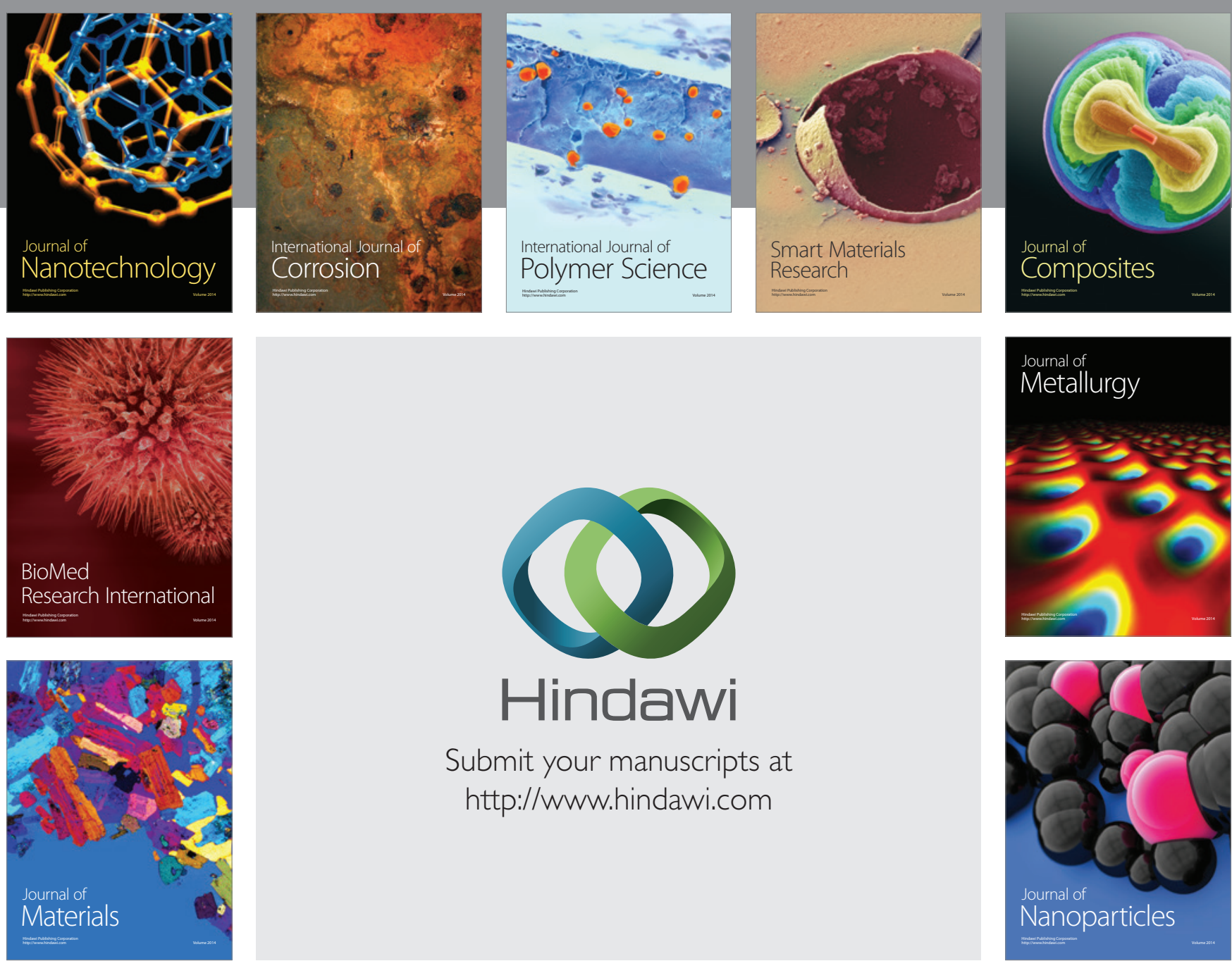

\section{Hindawi}

Submit your manuscripts at

http://www.hindawi.com

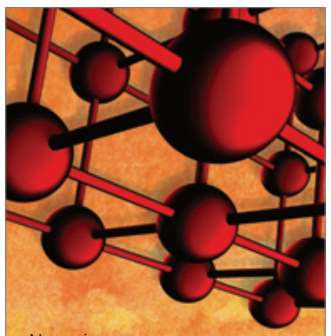

Materials Science and Engineering
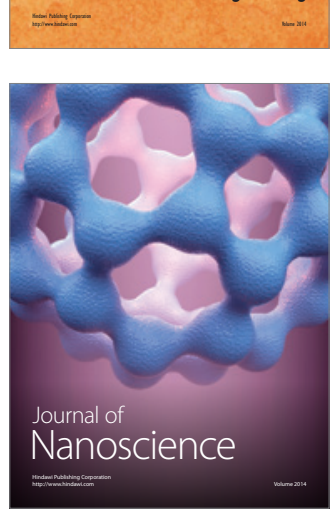
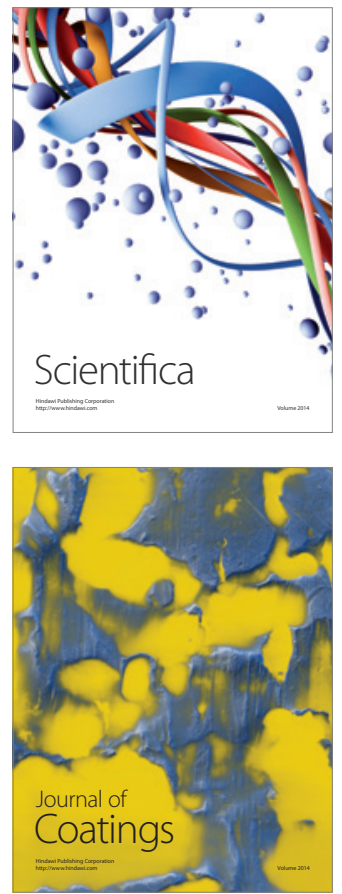
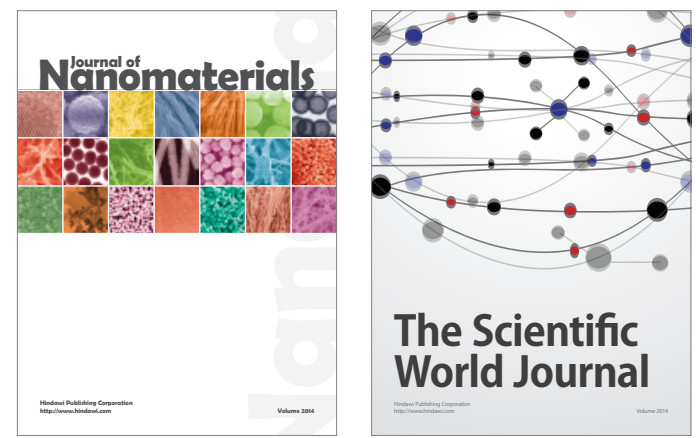

The Scientific World Journal
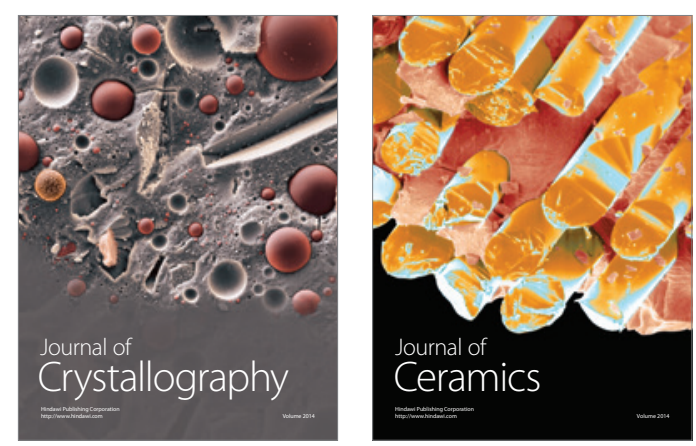
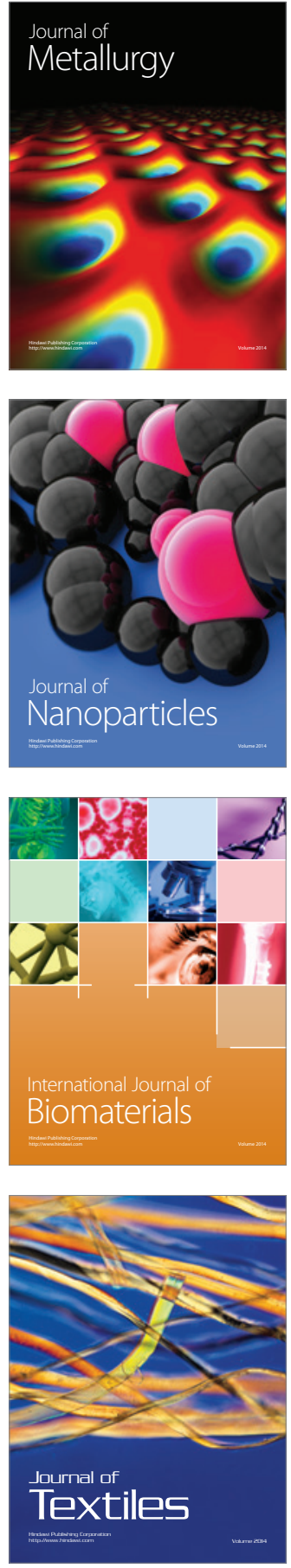